\title{
Generosity among the Ik of Uganda - Corrigendum
}

Cathryn Townsend, Athena Aktipis, Daniel Balliet and Lee Cronk

DOI: https://doi.org/10.1017/ehs.2020.22 Published online by Cambridge University Press: 14 May 2020

The authors apologise that a few typographical errors were included in the publication of the above article.

In Table 1, the mean for the NR (i.e. needy recipient) condition is 0.278 (not 0.253 ), the median for the Pun (i.e. punishment) condition is 0.25 (not 0.275), and the SD for the NR condition is 0.212 (not 0.221). In Figure 2, one person is missing from the column representing the number of people in the $\mathrm{nr}+$ pun (i.e. needy recipient plus supernatural punishment) condition who gave away $40 \%$ of their endowments. These errors have no impact on the article's findings or conclusions.

\section{Reference}

Townsend, C., Aktipis, A., Balliet, D., and Cronk, L., 2020. Generosity among the Ik of Uganda. Evolutionary Human Sciences, 2, 1-13.

\footnotetext{
Cite this article: Townsend C, Aktipis A, Balliet D, Cronk L (2021). Generosity among the Ik of Uganda - Corrigendum. Evolutionary Human Sciences 3, e7, 1-1. https://doi.org/10.1017/ehs.2021.3

(c) The Author(s), 2021. This is an Open Access article, distributed under the terms of the Creative Commons Attribution licence (http://creativecommons.org/licenses/by/4.0/), which permits unrestricted re-use, distribution, and reproduction in any medium, provided the original work is properly cited.
} 